\title{
Grooming pattern in captive Macaques: A comparative study
}

\author{
Lalremruati P., Lalchhuanawma and Solanki G. S. 网
}

Received: 05.10.2020

Revised: 11.11.2020

Accepted: 18.11.2020

\begin{abstract}
A comparative study on grooming behavior was done on three species of macaques, namely, Assamese macaque (Macaca assamensis), rhesus macaque (Macaca mulatta) and northern pig-tailed macaque (Macaca leonina) under captivity in Aizawl Zoological Park, Aizawl, India. Observations were recorded by Focal Sampling Technique. Time spent on different acts of grooming, and grooming visible and non-visible sites was recorded. Generally $75 \%$ of the time was spent on removal of ectoparasite and skin flakes (hygiene related acts). The time spent on various grooming acts varied in different age and sex categories in all three species. Time spent on grooming visible and non-visible sites was more in the Assamese macaque. Time spent on visible and non-visible site by all age and sex categories in all three species was found to be significant $(p<0.05)$. The pattern of variations on grooming visible and non-visible area was similar in all the species. Time spent on grooming non-visible sites was more than on the visible sites. Adult males and females spent more time on grooming visible areas in all the species. Dissimilarity among macaque species and between age and sex category in grooming visible areas was significant. Grooming site preference is predisposed by the sex and age of individuals.
\end{abstract}

Key Words: Captivity, Grooming, Macaque species, Non-visible sites, Pattern, Site Selection, Visible sites

\section{Introduction}

Grooming refers to the act of treading and manipulation of the body surface (Hutchins and Barash, 1976; Tanaka \& Takefushi, 1993) which encompasses all forms of care and attention (Saunders, 1988). It constitutes a major social activity in many species of social mammals (Mooring et al., 1996; Hart, 2000; Heitor et al., 2006) including rodents (Ferron and Lefebvre, 1982) and bats (Wilkinson, 1986). In primates, grooming is an integral part of life (Dunbar, 1988, 1991, 2010; Grueter et al., 2013). Some species of macaques (such as Macaca nemestrina, Macaca fasicularis, Macaca fuscata, Macaca mulatta, Macaca radiata), larger apes such as bonobo (Pan paniscus), chimpanzee ( Pan troglodytes), and baboon (Papio cynocephalus ) devote as much as $20 \%$ of their total daytime for grooming (Sparks, 1967; Goosen, 1987; Dunbar, 1991; Lehmann et al., 2007; Schino, 2007; Shutt et al., 2007). The social functions of grooming include the establishment and maintenance of affiliative relationships and the reduction of tension and aggression between individuals (Terry, 1970; Saunders, 1988; Kimura, 1998; Kutsukake and

\section{Author's Address}

Department of Zoology, Mizoram University, Aizawl, Mizoram

E-mail.: gssolanki02@yahoo.co.in
Clutton-Brock,2006). In addition to its hygienic functions, grooming is generally considered to maintain social bonds between group members (Dunbar, 1988; Henzi and Barrett, 1999; Schino and Aureli, 2008). Grooming also has important direct health consequences for wellbeing of primates via removal of ectoparasites such as lice, fleas, and ticks (Freeland, 1981; Saunders and Hausfater, 1988; Tanaka and Takefushi, 1993; Eckstein and Hart, 2000; Hart, 2000; Zamma, 2002; Kutsukake and Clutton-Brock, 2006). Several factors affect grooming patterns in animals, one of which is kinship. Kinship explains a large fraction of the variance in grooming patterns (Schino, 2001; Chapais and Berman, 2004). Seyfarth (1977) suggested that grooming is also directed by dominance hierarchy (i.e. preferential grooming of high-ranking animals). Other studies have documented increased grooming down the hierarchy (Obrien, 1993; Parr et al., 1997; LazaroPerea et al., 2004). These conflicting findings may result from differences in social and ecological contexts, which influence how resources are distributed in a social group. In different primate groups, participation in grooming bouts differs between the sexes and with life history stage. Some studies have considered grooming as a female- 
biased behavior established during the first year of life, with females grooming almost twice as often as males (Simonds, 1974; Young et al., 1982). Females tend to form strong social bonds with other females (Wrangham, 1980) and grooming becomes a major contributory factor to these social bonds (Silk et al., 2003, 2006, 2010). The age of an individual also plays a role in the amount of grooming received or given. In baboons, adult females initiate grooming bouts mostly (Saunders, 1988). Males provide important services, such as protection against infanticidal attacks and harassment (Smuts, 1985; Saunders, 1988; Silk et al., 2003; Nguyen, 2012) by peripheral males, females may be motivated to groom males in return for these services. Most of these differences referred to natural populations which encounter varied ecological situations. In captivity, animals may be less constrained by ecological limits with reduced time constraints. Captive primates can devote large proportion of their time in grooming (Leve et al., 2016). A study was planned to understand how different macaque species under similar environmental situation (in captivity) behave in grooming acts, and patterns. Do age, sex, and hierarchy in the captive groups exhibit specific preference in grooming site selection?

\section{Materials and Methods \\ Subjects and study site}

The study was conducted on captive primates inside the Aizawl Zoological Park, Aizawl, India. Seven species of primates: Macaca mulatta, Macaca assamensis, Macaca arctoides, Macaca leonina, Hoolock hoolock, Trachypithecus pileatus and Nycticebus bengalensis are maintained in the Zoo. Three macaque species, Assamese macaque (Macaca assamensis), rhesus macaque (Macaca mulatta), and northern pig-tailed macaque (Macaca leonina) were selected for this study. These groups were maintained in independent cages with floor area of $850 \mathrm{~m}^{2}$. All the groups were in multi-male and multi-female composition. The detailed composition of the group of each species studied is given in Table 1. All three species are presented in photoplate 1.

\section{Data collection and analyses}

The study was carried out during non breeding period for 2 months (April-May-2012). The data collection on acts, pattern, and site selection for grooming was recorded using Focal animal Sampling Technique (Altmann, 1974). Observations were recorded on a 10-minute interval basis per hour and for 11 hours in a day (7:00 a.m. to 6:00 p.m.), and 6 days in a week. Thus a total of 3168 observational episodes were recorded for each macaque species and 9504 episode for all macaques under study. Data collected on time spent on different grooming act by individuals of all sexes and age groups by each species was recorded and presented in terms of percentage. The variations among different sex and age groups in all the species was tested using Kruskal Wallis test, a nonparametric analysis of variance (ANOVA). Time spent on grooming different body sites was recorded in minutes. Grooming sites were divided into visible sites and non-visible sites. Visible site includes ventral part of upper arms, hand, chest, belly with genital region, feet, ventral part of legs and thigh, tail tip, fore arm. Non-visible site includes head and neck, face, shoulder, dorsal part of upper arm, dorsal area of legs and thigh, back with anal region. Variation in total time and the average time spent (minutes) grooming visible and non visible sites by three species was compared between the species using tested using one tailed ' $t$ ' - test. Variation in time spent by different sex and age group among three species was tested using Dunn's multiple comparison tests. Mann-Whitney $\mathrm{U}$ test was employed for the pair-wise comparison between different species.

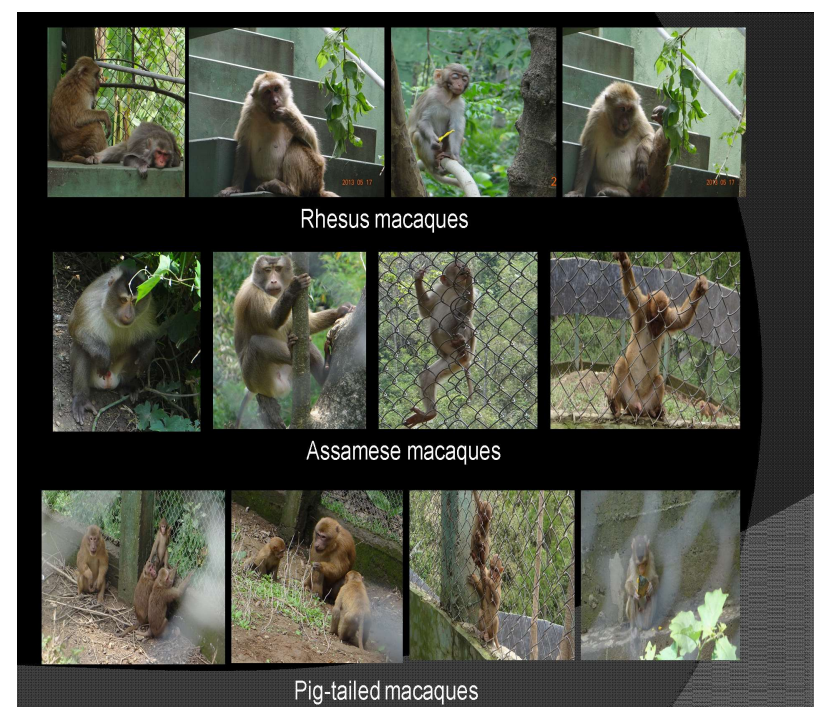

Photoplate 1. Representation ofmacaque species studied 


\section{Results and Discussion Acts of grooming}

The time spent (\%) on different acts of grooming (removal of ectoparasite, skin flakes, social function and sexual courtship) by different age group in the 3 species is given in Tables 2,3 and 4 respectively. Generally $62-64 \%$ of the time was spent on removal of ectoparasite (hygiene) and that was the major activity in captive macaques. Social function was the next important acts where macaque species spent $23-26 \%$ of time. Time on removal of skin flakes (dead skin cells) was also a hygiene related activity where time spent varied between $9-11 \%$ of total time spent on grooming. Thus in captive macaque hygiene upkeep was major purpose where they spent $70-75 \%$ of time. While grooming the groomer eats the parasite and the skin flakes are thrown away by the groomer.

Table 1. Age and sex composition of study groups

\begin{tabular}{|l|l|l|l|}
\hline \multirow{2}{*}{ Age group } & \multicolumn{3}{|c|}{ Number of individuals } \\
\cline { 2 - 4 } & Assamese macaque & Rhesus macaque & Northern pig-tailed macaque \\
\hline Adult male (AM) & 4 & 4 & 4 \\
\hline Adult female (AF) & 3 & 5 & 3 \\
\hline Juvenile male (JM) & 1 & 2 & 3 \\
\hline Juvenile female (JF) & 2 & 3 & 2 \\
\hline Infant (IF) & 2 & 2 & 2 \\
\hline Group size & 12 & 16 & 14 \\
\hline
\end{tabular}

Table 2.Time spent (\%) by individuals of different age and sex categories of Assamese macaque on different activities during grooming

\begin{tabular}{|l|l|l|l|l|l|l|}
\hline \multirow{3}{*}{ Activities } & \multicolumn{6}{|c|}{ Time spent (\%) } \\
\cline { 2 - 8 } & \multicolumn{6}{|c|}{ Assamese macaque } \\
\cline { 2 - 7 } & AM & AF & JM & JF & IF & Average time \\
\hline Removal of ectoparasite & 69.3 & 58 & 57.8 & 58.9 & 66.2 & $62.04( \pm 5.34)$ \\
\hline Skin flakes & 8.4 & 11.3 & 17.1 & 12.2 & 8.6 & $11.52( \pm 3.53)$ \\
\hline Social function & 20.2 & 20.2 & 29.1 & 22.7 & 27.3 & $23.9( \pm 4.1)$ \\
\hline Sexual courtship & 2.1 & 1.6 & 2.5 & 1.4 & 0 & $1.52( \pm 0.95)$ \\
\hline
\end{tabular}

(Kruskal Wallis Value $(\mathrm{H})=17.871, \mathrm{P}<0.01)$

Table 3. Time spent (\%) by individuals of different age and sex categories of rhesus macaque on different activities during grooming

\begin{tabular}{|l|l|l|l|l|l|l|}
\hline \multirow{2}{*}{ Purpose } & \multicolumn{7}{|c|}{ T Time spent (\%) } \\
\cline { 2 - 8 } & \multicolumn{9}{|c|}{ Rhesus Macaque } \\
\cline { 2 - 8 } & AM & AF & JM & JF & IF & Average time \\
\hline Removal of ectoparasite & 65.1 & 61.7 & 60.5 & 61.7 & 63.1 & $62.42( \pm 1.75)$ \\
\hline Skin flakes & 11 & 8.4 & 10.8 & 9.2 & 9.2 & $9.72( \pm 1.12)$ \\
\hline Social function & 21.1 & 26.6 & 26.4 & 26.9 & 27.6 & $25.72( \pm 2.62)$ \\
\hline Sexual courtship & 2.7 & 3.2 & 2.3 & 2.1 & 0 & $2.06( \pm 1.22)$ \\
\hline
\end{tabular}

(Kruskal Wallis Value $(\mathrm{H})=17.884, \mathrm{P}<0.01)$

Table 4. Time spent (\%) by individuals of different age and sex categories of northern pig-tailed macaque on different activities during grooming

\begin{tabular}{|l|l|l|l|l|l|l|}
\hline \multirow{2}{*}{ Purpose } & \multicolumn{7}{|c|}{ Torthern Pigtailed Macaque } \\
\cline { 2 - 8 } & AM & AF & JM & JF & IF & Average time \\
\hline Removal of ectoparasite & 62.6 & 65.2 & 65.2 & 63.8 & 65.6 & $64.48( \pm 1.25)$ \\
\hline Skin flakes & 13.2 & 11.3 & 11.2 & 9.6 & 10.7 & $11.2( \pm 1.3)$ \\
\hline Social function & 21.9 & 22.6 & 20.8 & 24.8 & 23.7 & $22.76( \pm 1.55)$ \\
\hline Sexual courtship & 2.2 & 0.8 & 2.6 & 1.6 & 0 & $1.44( \pm 1.05)$ \\
\hline
\end{tabular}

Kruskal Wallis Value $(\mathrm{H})=17.871, \mathrm{P}<0.01$ ) 


\section{Lalremruati et al.}

The variation in times spent for various acts of grooming by different age and sex categories by each species was tested using Kruskal Wallis test and found highly significant $(\mathrm{P}<0.01)$ in all three species (Table 2, 3, 4). Very less time spent on sexual courtship in all the cases. Grooming for sexual courtship always ended with an unsuccessful mounting attempt, therefore, it can be distinguished from grooming for social function. The time spent on grooming for different acts by all three species were almost similar and no inter-specific variations were apparently evident.

\section{Site of grooming}

\section{Visible sites}

The time spent on grooming visible sites by different age and sex groups of the 3 species is given in Table 5. Average time spent on grooming visible sites by Assamese macaque was more (1140 $\mathrm{min})$, followed by rhesus macaque (1068 $\mathrm{min}$ ) and northern pig-tailed macaque (924 $\mathrm{min})$. Average time spent on grooming visible areas varied significantly $(\mathrm{p}<0.01)$ across the species and Assamese macaques spent more time on grooming visible areas than other two species. Total time spent on visible areas by different age and sex categories of each macaque species was tested using Dunn's multiple comparison tests. Each macaque species spent time on grooming visible areas was different and the variations found significant $(\mathrm{p}<0.05)$ however Assamese macaque spent more time on grooming visible area (Table 5). Pair-wise comparison was done using ManWhitney test (Table 6). Adult females of Assamese macaques and rhesus macaques spent more time $(p<0.01)$ than females of northern pigtailed macaques. Similarly, juvenile males of Assamese macaques and rhesus macaques also spent more time $(\mathrm{p}<0.01)$ grooming visible sites in comparison to northern pigtailed macaque (Table 3 ). The infants of Assamese macaques spent more time on grooming visible area as compare to the infants of northern pigtailed macaques $(p<0.01)$. However, the infants of Assamese macaques, rhesus macaques and northern pigtailed macaques; the adult males and juvenile females of Assamese macaques, rhesus macaques and northern pigtailed macaques did not show significant variation on the amount of time spent on grooming visible areas. Adult males spent almost equal time on grooming visible areas in all the species. The variations among macaque species grooming visible areas were significant; age and sex are major factors leading to these variations.

\section{Non-visible area}

The time spent on grooming non-visible areas by different age groups of the 3 species is given in Table 7. Assamese macaque spent an average time (1642 $\mathrm{min})$ on grooming non-visible areas was more than rhesus macaque (1600 $\mathrm{min})$ and northern pig-tailed macaque $(1382 \mathrm{~min})$ and the variation was found to be significant $(p<0.01)$ across the species. Total time spent on non-visible area by age and sex categories of each macaque species was different across the categories. Assamese macaque spent significant more time on grooming nonvisible area; this was tested using Dunn's multiple comparison tests and the variation found significant $(\mathrm{p}<0.05)$. Pair-wise comparison was done using Man-Whitney $\underline{U}$ test (Table 8). Pair-wise comparison revealed that the adult males of Assamese macaques and rhesus macaques spent significantly more time $(\mathrm{p}<0.01)$ on grooming nonvisible sites than the adult males of northern pigtailed macaques. The adult females of Assamese macaque spent more time $(p<0.05)$ on grooming non-visible sites than the adult females of other two macaques. The infants of Assamese macaques and rhesus macaques spent more time $(\mathrm{p}<0.01)$ on grooming non-visible sites than the infants of northern pigtailed macaques. However, the infants of rhesus macaques and Assamese macaques did not show significant variation in the time spent on grooming non-visible sites. The juvenile males and juvenile females of Assamese macaques, rhesus macaques and northern pigtailed macaques did not show significant variation. Age is not a contributory factor for time spent on grooming nonvisible sites

\section{Comparison of time spent on visible and non- visible sites}

The pattern of variations on grooming visible and non-visible area was similar. All macaques spent more time on non-visible sites; however variations among species were distinct. Assamese macaque spent more time and northern pig-tailed macaques spent less time on grooming. Paired t-test was carried out to compare the time spent on grooming visible sites and non-visible sites and comparison was found significant $(p<0.001)$. 
Table 5. Time spent on grooming visible areas among different age and sex categories by each macaque species.

\begin{tabular}{|c|c|c|c|c|c|c|c|}
\hline \multirow{2}{*}{$\begin{array}{l}\mathbf{S} \\
\mathbf{N}\end{array}$} & \multirow[b]{2}{*}{ Name of species } & \multicolumn{5}{|c|}{ Duration of grooming (minutes) } & \multirow[b]{2}{*}{ Average time* } \\
\hline & & $\begin{array}{l}\text { Adult } \\
\text { male }\end{array}$ & $\begin{array}{l}\text { Adult } \\
\text { female }\end{array}$ & $\begin{array}{l}\text { Juvenile } \\
\text { male }\end{array}$ & $\begin{array}{l}\text { Juvenile } \\
\text { female }\end{array}$ & Infant & \\
\hline 1 & Assamese macaque & 770 & 980 & 1210 & 1200 & 1540 & $1140 \pm(287.66)$ \\
\hline 2 & Rhesus macaque & 720 & 1120 & 1020 & 1120 & 1360 & $1068( \pm 231.34)$ \\
\hline 3 & Northern pig-tailed macaque & 600 & 860 & 920 & 1020 & 1220 & $924( \pm 226.89)$ \\
\hline
\end{tabular}

$*(\mathrm{p}<0.001)$

Table 6. The pair-wise comparison test for grooming visible areas among age and sex group in the different macaque species.

(* Significance level) $\mathrm{U}=$ Mann-whitney value, $\mathrm{W}=$ Wilcoxon value, $\mathrm{p}=$ probability value

\begin{tabular}{|l|l|l|l|l|}
\hline SN & Individual pairs & $\mathbf{U}$ & $\mathbf{W}$ & $\mathbf{P}$ \\
\hline 1 & Adult female of Assamese and rhesus macaque & 440 & 905 & 0.878 \\
\hline 2 & Adult female of Assamese and northern pig-tailed macaque & 70 & 535 & $\mathbf{0 . 0 0 1}$ \\
\hline 3 & Adult female of northern pig-tailed and rhesus macaque & 42 & 507 & $\mathbf{0 . 0 0 1 *}$ \\
\hline 4 & Juvenile male of Assamese and rhesus macaque & 331 & 796 & 0.072 \\
\hline 5 & Juvenile male of rhesus and northern pig-tailed macaque & 186 & 486 & $\mathbf{0 . 0 0 2}$ \\
\hline 6 & Juvenile male of Assamese and northern pig-tailed macaque & 287 & 752 & $\mathbf{0 . 0 1 3}$ \\
\hline 7 & Infant of Assamese and rhesus macaque & 410.5 & 875.5 & 0.549 \\
\hline 8 & Infant of rhesus and northern pig-tailed macaque & 268.5 & 733 & 0.086 \\
\hline 9 & Infant of Assamese and northern pig-tailed macaque & 196.5 & 661.5 & $\mathbf{0 . 0 0 1 *}$ \\
\hline
\end{tabular}

Table 7. Time spent on grooming non-visible areas among different age and sex categories by each macaque species

\begin{tabular}{|c|c|c|c|c|c|c|c|}
\hline \multirow[b]{2}{*}{ SN } & \multirow[b]{2}{*}{ Name of species } & \multicolumn{5}{|c|}{ Duration of grooming (minutes) } & \multirow[b]{2}{*}{ Average time } \\
\hline & & $\begin{array}{l}\text { Adult } \\
\text { male }\end{array}$ & $\begin{array}{l}\text { Adult } \\
\text { female }\end{array}$ & $\begin{array}{l}\text { Juvenile } \\
\text { male }\end{array}$ & $\begin{array}{l}\text { Juvenile } \\
\text { female }\end{array}$ & Infant & \\
\hline 1 & Assamese macaque & 1640 & 1750 & 1480 & 1680 & 1660 & $1642 \pm 99.59$ \\
\hline 2 & Rhesus macaque & 1380 & 1900 & 1500 & 1620 & 1600 & $1600 \pm 192.87$ \\
\hline 3 & Northern pig-tailed macaque & 1320 & 1440 & 1360 & 1490 & 1300 & $1382 \pm 80.74$ \\
\hline
\end{tabular}

$*(p<0.001)$

Table 8. The pair-wise comparison test for grooming non-visible areas among age and sex group in the different macaque species

\begin{tabular}{|l|l|l|l|l|}
\hline SN & Individual pairs & $\mathbf{U}$ & $\mathbf{W}$ & $\mathbf{P}$ \\
\hline 1 & Adult male of Assamese and rhesus macaque & 280 & 745 & $\mathbf{0 . 0 1 0}$ \\
\hline 2 & Adult male of rhesus and northern pig-tailed macaque & 187 & 652 & $\mathbf{0 . 0 0 1}^{*}$ \\
\hline 3 & Adult male of Assamese and northern pig-tailed macaque & 414 & 879 & $\mathbf{0 . 5 6 0}^{*}$ \\
\hline 4 & Adult female of Assamese and rhesus macaque & 422 & 587 & 0.66 \\
\hline 5 & Adult female of Assamese and northern pig-tailed macaque & 328 & 793 & $\mathbf{0 . 0 5 0}^{*}$ \\
\hline 6 & Adult female of pig-tailed macaque and rhesus macaque & 338 & 803 & 0.08 \\
\hline 7 & Infant of Assamese and rhesus macaque & 426 & 891 & 0.713 \\
\hline 8 & Infant of rhesus and northern pig-tailed macaque & 221 & 686 & $\mathbf{0 . 0 0 1}^{*}$ \\
\hline 9 & Infant of Assamese and northern pig-tailed macaque & 240 & 705 & $\mathbf{0 . 0 0 1}^{*}$ \\
\hline
\end{tabular}

(* Significance level) $\mathrm{U}=$ Mann-whitney value, $\mathrm{W}=$ Wilcoxon value, $\mathrm{p}=$ probability value)

Grooming was assumed to have originally evolved Takefushi, 1993; Zamma, 2002; Akinyi et al., for hygienic purpose: removing debris and 2013). The act of grooming and amount of time ectoparasites from the hair and skin (Tanaka and spent for each activity varied significantly across 


\section{Lalremruati et al.}

the age and sex categories within group of each macaque species studied (Table 2, 3, 4). Nearly $75 \%$ of their time was spent in up-keeping of body hygiene by all the species, a major activity during grooming. Inter specific variations on time spent on hygienic needs by all age groups was almost equal, no significant variations were evident. Results of this study indicates that all the three macaque species (Assamese macaque, rhesus macaque and northern pig-tailed macaque) of all age group showed that the grooming is mainly for their hygienic needs followed by social function in captivity. The early studies also suggested that grooming is assumed to satisfy an individual's hygienic needs such as removal of ectoparasite, skin flakes and debris (Hutchins and Barash 1976; Barton, 1985). A study conducted by Rodrigues and Boeving (2019) on captive chimpanzee and bonobos indicated that in absence of ecological constraints primates showed similarity in grooming behavior and exhibited behavior plasticity. Other research in captive setting also reported that grooming is affected by individual histories and management practices (Stevens et al., 2006). Individuals with atypical rearing histories are less extraverted and groom less than the individuals who are mother reared (Freeman and Ross, 2014; Freeman et al., 2016). Social grooming was next important activity with an average of $25 \%$ time spent on that. Group cohesion and mother-infant social bond strengthen are major achievement of social grooming. A history of individuals under this study was not well known and therefore it appears that all individuals were mother reared hence intraindividual variations on acts of grooming were not distinct. However, among macaques, northern pigtailed macaque spent comparatively more time $(98.44 \%)$ on hygiene and social grooming than Assamese macaque and rhesus macaque. But this pattern of inter-specific grooming behavior is also not significant. This study clearly indicates that captive group of macaques undertakes grooming for maintaining body hygiene during non mating period. Time spent for courtship activity was negligible in all cases because no breeding/successful mating was observed. Period of this study was a non breeding season for Macaca assamensis (Mitra and Alfred, 2007), Macaca mulatta (Southwick et al., 1961). Macaca leonina is not seasonal breeder however a peak breeding activity of this species does not fall within the period of this study (Feeroz, 2003).

In monkeys, body site preference during social grooming are also known to be influenced by social variables such as levels of affiliation between individuals, strength of social bond and their dominance level (Allanic et al., 2020). In longtailed macaques (Macaca fascicularis), femalefemale dyads focus their grooming on face and frontal areas and in contrast to this male-male dyads preferred grooming back and tail (Moser et al., 1991). In rhesus macaques (Macaca mulatta) and hanuman langur (Semnopethicus entellus) dominance influenced body site preference, low ranking groomees tending to face away from high ranking groomer (Boccia et al., 1989; Borries, 1992). The present study shows that the macaques spent more time grooming on non-visible areas than visible area. Preference of site during grooming in all the three species is strong and significant. Assamese macaques (M. assamemsis) spent more time grooming visible and non-visible areas than rhesus macaques (M. mulatta) and northern pigtailed macaques ( $M$. leonina). Adult females, juveniles, and infants spent more time grooming visible area than males. Age and kinship also influenced the site selection. This was also confirmed by Allanic et al. (2020) for wild bonobos (Pan paniscus). Time for grooming non-visible /inaccessible areas was not similar as visible areas but the pattern in variation of time among the three macaque species was same; Assamese macaques (M. assamemsis) spent more time than other two species and females spent more time than males. However, grooming of inaccessible/invisible body sites goes along with position in which groomer and groomee face away from each other. Thus, the groomee might present its back to a groomer in order to prevent the release of aggression due to eye contact (Boccia et al., 1989). In the present study, the adult males show highest difference between grooming visible and non-visible area and followed by adult females, juveniles, and infant. This difference may be due to the ranking or age. On other hand, the infants who are mostly groomed by his/her mother and do not show any significant difference between grooming visible and nonvisible area. This clearly indicates that grooming site preference is reflected by the ranking or age of individuals. 


\section{Grooming pattern in captive Macaques}

\section{Conclusion}

Major act of grooming in captive macaque is hygiene upkeep; they spent $70-75 \%$ of time. The variation in times spent for various acts of grooming significantly varied in age and sex categories by each species. The present study shows that the macaques spent more time grooming on non-visible areas than visible area. Preference of site during grooming in all the three species is strong and significant. Assamese macaques ( $M$. assamemsis) spent more time grooming visible and non-visible areas than rhesus macaques ( $M$. mulatta) and northern pig-tailed macaques ( $M$. leonina). Grooming site preference is affected by the ranking or age of individuals. Captive

\section{References}

Akinyi, M. Y., Tung, J. J., Jeneby, M., Patel, N. B., Altmann, J. and Alberts, S. C. 2013. Role of grooming in reducing tick load in wild baboons (Papio cynocephalus). Animal Behaviour, 8: 559-568.

Allanic, M., Hayashi, M., Furuich, T. and Matsuzawa, T. 2020. Social influences on grooming site preferences in wild bonobos (Pan paniscus) at Wamba, DRC. Primates, 61: 213-223.

Altmann, J. 1974. Observational study of behaviour: Sampling methods. Behaviour, 49: 227-267.

Aureli, F., Preston, S. D. and de Waal , F. B. M. 1999. Heart rate responses to social interactions in free-moving rhesus macaques (Macaca mulatta): a pilot study. Journal of Comparative Psychology, 113: 59-65.

Barton, R. A. 1985. Grooming site preferences in primates and their functional implications. International Journal of Primatology, 6: 519-532.

Boccia, M. L. 1989. Comparison of physical characteristics of grooming in two species of macaques (Macaca nemestrina and M. radiata). Journal of Comparative Psychology, 103: 177-183.

Boccia, M. L., Reite, M. and Laudenslager, M. 1989. On the physiology of grooming in a Pig-tailed macaque. Physiological Behavior, 45: 667-670.

Borries, C. 1992. Grooming site preference in female langurs (Presbytis entellus). International Journal of Primatology, 13: 19-32.

Chapais, B. and Berman, C. 2004. Kinship and Behavior in Primates. Oxford University Press, New York. environment of Zoo also plays a role in variation of pattern and acts during grooming.

\section{Acknowledgement}

Authors are highly thankful to the authority of Mizoram University for providing academic and logistic support. We are also grateful to the Chief Wildlife Warden, Department of Environment, Forest and Climate Change, Government of Mizoram for according valid permission vide letter no.A.33011/4/2011-WLW/vol-II/3888-89 to carry out this research on captive primates and other support extended by park staff during study. Due acknowledgement is recorded to DST for awarding INSPIRE Fellowship to first author to carry out the research.

Dunbar, R. I. M. 1988. Primate social systems. Comstock Publishing Associates. Croom Helm Limited, Ithaca, New York.

Dunbar, R. I. M. 1991. Functional significance of social grooming in primates. Folia Primatologica, 57: 121-131.

Dunbar, R. I. M. 2010. The social role of touch in humans and primates: Behavioural function and neurobiological mechanisms. Neuroscience \& Biobehavioral Reviews, 34: 260-268.

Eckstein, R. A. and Hart, B. L. 2000. Grooming and control of fleas in cats. Applied Animal Behaviour Science, 68: 141150.

Ferron, J. and Lefebvre, L. 1982. Comparative organization of grooming sequences in adult and young sciurid rodents. Behaviour, 81: 110-127.

Freeman, H. D. and Ross, S. R. 2014. The impact of atypical histories on pet or performer chimpanzee. Peer J., 2: e579.

Freeman, H. D., Weiss, A. and Ross, S. R. 2016. Atypical early histories predict lower extraversion in captive chimpanzee. Developmental Psychobiology, 58: 519-527.

Freeland, W. J. 1981. Functional aspects of primate grooming. Ohio Journal of Science, 81: 173-177.

Feeroz, M. M. 2003. Breeding activities of pig-tailed macaque (Macaca leonina) in Bangladesh. Zoo's Print Journal, 18(8): 1175-1179.

Goosen, C. 1987. Social grooming in primates, pp.107-131. In: Mitchell, G. \& J. Erwin (eds.). Comparative Primates Biology, Vol. 2, Part B: Behavior, Cognition and motivation. Alan R. Liss, New York. 


\section{Lalremruati et al.}

Grueter, C. C., Li, D., Ren, B. and Li, M. 2013. Overwintering strategy of Yunnan snub-nosed monkeys: Adjustments in activity scheduling and foraging patterns. Primates, 54: 125-135.

Hart, B. 2000. Role of grooming in biological control of ticks. Annals of the New York Academy of Sciences, 916: 565569.

Heitor, F., Oom, M. D. and Vicente, L. 2006. Social relationships in a herd of Sorraia horses. Part II. Factors affecting affiliative relationships and sexual behaviours. Behavioural Processes, 73: 231-239.

Henzi, S. P. and Barrett, L. 1999. The value of grooming to female primates. Primates, 40: 47-59.

Hutchins, M. and Barash, D. P. 1976. Grooming in primates: implications for its utilitarian function. Primates, 17: 145150.

Kimura, R. 1998. Mutual grooming and preferred associate relationships in a band of free-ranging horses. Applied Animal Behaviour Science, 59: 265-276.

Kutsukake, N. and Clutton-Brock, T. 2006. Aggression and submission reflect reproductive conflict between females in cooperatively breeding meerkats. Suricata suricatta. Behavioral Ecology and Sociobiology, 59(4): 541-548.

Lazaro-Perea, C., de Fátima Arruda, M. and Snowdon, C. T. 2004. Grooming as a reward? Social function of grooming between females in cooperatively breeding marmosets. Animal Behaviour, 67: 627-636.

Lehmann, J., Korstjens, A. H. and Dunbar, R. I. M. 2007. Group size, grooming and social cohesion in primates. Animal Behaviour, 74: 1617-1629.

Leve, M., Sueur, C., Petit, O., Matsuzawa, T. and Hirata, S. 2016. Social grooming network in captive chimpanzee: does the wild and captive origin of group members affect sociality? Primates, 57: 73-82.

Mitra, S. and Alfred, J. R. B. 2007. Reproductive behavior of the Assamese macaque (Macaca assamensis) in Darjeeling district, India. Records of Zoological Survey of India, 107(Part-4): 33-42.

Mooring, M. S., McKenzie, A. A. and Hart, B. L. 1996. Grooming in impala: role of oral grooming in removal of ticks and effects of ticks in increasing grooming rate. Physiology and Behavior, 59: 965-971.

Moser, R., Cords, M. and Kummer, H. 1991. Social influence on grooming site preference among captive long-tailed macaques. International Journal of Primatology, 12: 217230. wild baboons: social, experiential and hormonal correlates. Animal Behaviour, 83: 891-903.

Obrien, T. G. 1993. Allogrooming behavior among adult female wedge-capped capuchin monkeys. Animal Behaviour, 46: 499-510.

Parr, L. A., Matheson, M. D., Bernstein, I. S. and Waal, F. B. M. 1997. Grooming down the hierarchy: allogrooming in captive brown capuchin monkeys, Cebus apella. Animal Behaviour, 54: 361-367.

Rodrigues, M. A. and Boeving, E. R. 2019. Comparative social grooming networks in captive chimpanzee and bonobos. Primates, 60: 191-202.

Saunders, C. D. 1988. Ecological, social, and evolutionary aspects of baboon grooming behavior. Ph.D. thesis submitted to Cornell University, USA

Saunders, C. D. and Hausfater, G. 1988. The functional significance of baboon grooming behavior. Annals of the New York Academy of Sciences, 525: 430-432.

Schino, G. 2001. Grooming, competition and social rank among female primates: a meta-analysis. Animal Behaviour, 62: 265-271.

Schino, G. 2007. Grooming and agonistic support: a metaanalysis of primate reciprocal altruism. Behavioral Ecology, 18: 115-120.

Schino, G.and Aureli, F. 2008. Grooming reciprocation among female primates: a meta-analysis. Biology Letters, 4: 9-11.

Seyfarth, R. M. 1977. Model of social grooming among adult female monkeys. Journal of Theoretical Biology, 65: 671698.

Shutt, K., MacLarnon, A., Heistermann, M. and Semple, S. 2007. Grooming in Barbary macaques: better to give than to receive? Biology Letters, 3: 231-233.

Silk, J. B., Alberts, S. C. and Altmann, J. 2003. Social bonds of female baboons enhance infant survival. Science, 302: 1231-1234.

Silk, J. B., Alberts, S. C. and Altmann, J., 2006. Social relationships among adult female baboons (Papio cynocephalus). II. Variation in the quality and stability of social bonds. Behavioral Ecology and Sociobiology, 61: 197-204.

Silk, J. B., Beehner, J. C., Bergman, T. J., Crockford, C., Engh, A. L., Moscovice,L. R., Wittig, R. M., Seyfarth, R. M. and Cheney, D. L. 2010. Strong and consistent social bonds enhance the longevity of female baboons. Current Biology, 20: $1359-1361$.

Nguyen, N., Gesquiere, L., Alberts, S. C. and Altmann, J. 2012. Sex differences in the mothereneonate relationship in 


\section{Grooming pattern in captive Macaques}

Simonds, P. E. 1974. Sex differences in bonnet macaque networks and social structure. Archives of Sexual Behavior, 3: 151-166.

Smuts, B. 1985. Sex and Friendship in Baboons. Hawthorne: Aldine Press.

Southwick, C. M., Beg, M. A. and Siddiqi, M. R. 1961. A population survey of rhesus monkeys in northern India. Part II, Transportation routes and forest areas. Ecology, 42: 698-710.

Sparks, J. 1967. Allogrooming in primates: A review, pp.148175. In: D. Morris (Ed.). Primate Ethology. Weidenfeld and Nicholson, London.

Stevens, J. M. G., Vervaecke, H., De Vries, H. and Van Elsacker, L. 2006. Social structure in Pan paniscus: testing female bonding hypothesis. Primates, 47: 210-217.

Tanaka, I. and Takefushi, H. 1993. Elimination of external parasites (lice) is the primary function of grooming in free- ranging Japanese macaques. Anthropological Science, 101: 187-193.

Terry, R. L. 1970. Primate grooming as a tension reduction mechanism. Journal of Psychology, 76: 129-136.

Wilkinson, G. S. 1986. Social grooming in the common vampire bat, Desmodus rotundus. Animal Behaviour, 34: 1880-1889.

Wrangham, R. W. 1980. An ecological model of femalebonded primate groups. Behaviour, 75: 262-300.

Young, G., Coelho, A. M. and Bramblett, C. A. 1982. The development of grooming, sociosexual behavior, play and aggression in captive baboons in their first two years. Primates, 23: 511-519.

Zamma, K. 2002. Grooming site preferences determined by lice infection among Japanese macaques in Arashiyama. Primates, 43: 41-49. 